ARTICLE

\title{
Twitter: A tool to improve healthcare professionals' awareness of antimicrobial resistance and antimicrobial stewardship
}

\author{
D A Goff, ${ }^{1}$ PharmD, FCCP; D van den Bergh, ${ }^{2}$ BPharm, MSc (Med), EngD \\ ${ }^{1}$ Department of Pharmacy, The Ohio State University Wexner Medical Center, Columbus, OH, USA \\ ${ }^{2}$ Director of Quality Leadership, Netcare Ltd, South Africa
}

Corresponding author: D A Goff(debbie.goff@osumc.edu)

The World Health Organization urges international collaboration for the containment of antimicrobial resistance (AMR) or 'superbugs'. If left unchecked, AMR could result in 4.1 million deaths in Africa by 2050. Furthermore, without effective antibiotics, surgical procedures would become much riskier and in many cases impossible. Antimicrobial stewardship requires a multidisciplinary approach; however, many programmes still struggle to achieve the 'reach' required to educate and engage all healthcare providers (HCPs). Twitter use among South Africans has grown by $129 \%$ in 12 months, from 2.4 million to 5.5 million. HCPs can use Twitter to network and connect with worldwide experts, obtain real-time news from medical conferences, participate in live Twitter chats conducted by experts or medical organisations, or participate in international journal clubs. Used responsibly and professionally, Twitter can spread the call to action and connect frontline healthcare professionals to help win the battle against AMR.

S Afr Med J 2015;105(5):420. DOI:10.7196/SAMJ.9648

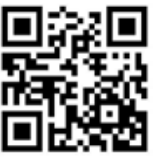

A special report published in the New England Journal of Medicine, "Health and health care in South Africa 20 years after Mandela, describes the urgent need to increase the number of healthcare professionals and reflects on some of the major challenges to improving health in South Africa (SA) ${ }^{[1]}$ HIV and tuberculosis lead the list of challenges. However, antimicrobial resistance (AMR) has emerged as an additional challenge. On 17 May 2014 the World Health Organization (WHO) declared that antibiotic resistance threatens the achievements of modern medicine ${ }^{[2]} \mathrm{WHO}$ recommended several resolutions, including to improve among all relevant care providers, the public sector and other sectors and stakeholders awareness of (i) the threat posed by AMR, (ii) the need for responsible use of antibiotics'. No single strategy will contain the emergence and spread of antibiotic-resistant organisms.

(Click on the following link to listen to an interview by the New England Journal of Medicine with Otto Cars, MD, $\mathrm{PhD}$, on 'The prospects for combating antibiotic resistance': http://www.nejm.org/ doi/full/10.1056/NEJMp1408040.)

The SA Antibiotic Stewardship Programme (SAASP) implemented stewardship programmes to promote appropriate antimicrobial prescribing across public and private health sectors. ${ }^{[3]}$ Effective antimicrobial stewardship (AMS) requires a multidisciplinary approach with local 'champions'. Despite numerous publications documenting escalating AMR, antibiotic misuse continues worldwide. The 2014 United States Centers for Disease Control and Prevention (CDC) Vital Signs Report found that 50\% of hospitalised patients receive an antibiotic, one-third of vancomycin prescriptions included an error, and physicians in some hospitals prescribe up to three times as many antibiotics as physicians in similar hospitals. ${ }^{[4]}$ This difference suggests there is room for improvement.

A recent commentary in Lancet Infectious Diseases on the topic of appropriate antimicrobial use asked, 'How do we get the message into the hands of non-infectious diseases orientated surgeons, oncologists, and other high users of antimicrobials who we are failing to reach?' ${ }^{[5]}$
They suggest that social media, using Twitter, may be one of the answers. The purpose of this article is to describe how Twitter can be used to educate and engage all healthcare providers (HCPs) in AMS.

\section{Methods}

A PubMed search between 2006 and 2014 using the phrase 'Twitter and healthcare providers' yielded 41 unique articles of which $32 \%$ were published during the last 2 years. A Google search in 2014 using the phrase 'twitter and physicians' yielded multiple blogs and websites. A personal archive of references on AMR and AMS was accessed. Personal communication with healthcare Twitter 'experts' was also used.

\section{What is the impact of antimicrobial resistance?}

A 2014 report commissioned by the British Prime Minister modelled that if AMR or 'superbugs' are left unchecked, it could result in 4.1 million deaths in Africa and $>10$ million deaths worldwide by $2050 .{ }^{[6]}$ If we fail to contain AMR, surgery will become far more dangerous in a world that relies on prophylactic antibiotics.

\section{How is social media used in South Africa?}

According to the SA Social Media Landscape 2014 research report, Facebook is the largest social network in SA, with 9.4 million active users. ${ }^{[7]}$ Twitter's use among South Africans saw the highest percentage growth among the major social networks, from 2.4 million to 5.5 million (129\% growth) in 12 months. Interestingly, $85 \%$ of Twitter users access this tool on their phones. With the accessibility of cheap smartphones (for ZAR500), the economic and social impact of access not only on smartphones, but also on instant internet, is a game-changer for SA. In addition, the use of the photosharing and special effects app Instagram has exploded in SA, from below 100000 in 2011 to 680000 in 2013. 


\begin{abstract}
Why should healthcare providers consider Twitter for antimicrobial stewardship?

Twitter was founded in 2006 as a free social networking tool. Users may write or read posts known as 'tweets', that are limited to 140 characters. Unlike Facebook, Twitter users do not have to mutually connect with each other. Users may choose who they want to follow. HCPs can follow experts in their fields, medical journals, professional organisations or patient advocacy groups. The value of Twitter for AMS is in the potential dissemination of information in terms of the number of people it is able to reach. Fig. 1 shows how a tweet is disseminated throughout one's network of followers.

Many frequent prescribers of antibiotics (surgeons and oncologists) do not read infectious diseases journals, where the majority of AMR and AMS articles are published. Twitter provides a vehicle to connect HCPs with each other. A tweet can spread rapidly and widely to a large network. This was demonstrated during the 2014 Ebola epidemic. There were $>10$ million tweets in 3 weeks from 170 countries mentioning the word 'Ebola. ${ }^{[8]}$ Frontline HCPs and citizens from West Africa were tweeting about Ebola in real-time, providing insight
\end{abstract}

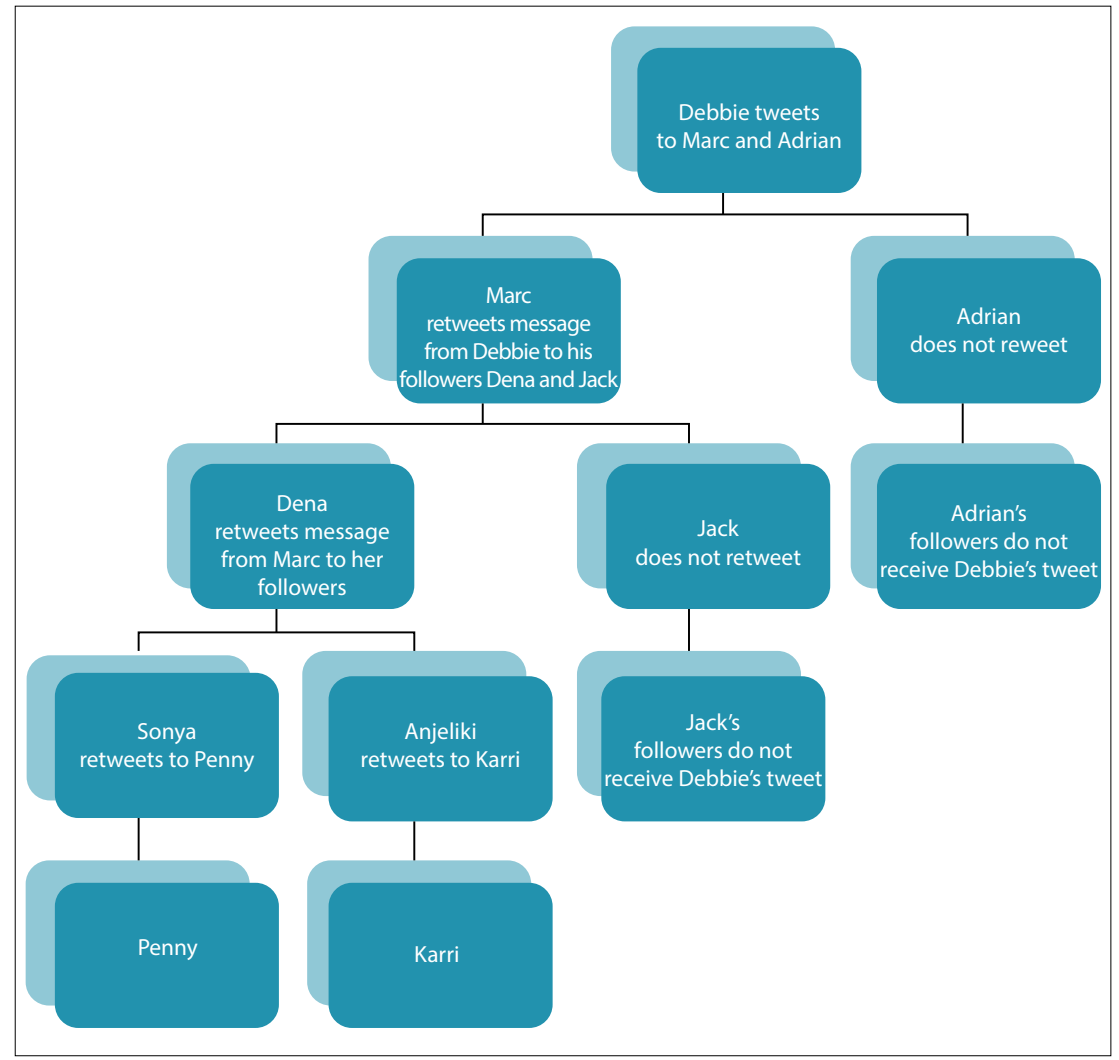

Fig. 1. Dissemination of a tweet.

Table 1. Selected people, organisations and medical journals to follow on Twitter

\begin{tabular}{|c|c|c|}
\hline Name & Twitter name & Description \\
\hline Debra Goff, PharmD & @idpharmd & Infectious diseases pharmacist; global AMS educator; international advisor to SAASP \\
\hline Marc Mendelson, MD & @SouthAfricanASP & $\begin{array}{l}\text { Co-chair SAASP; President of the Federation of Infectious Diseases Societies of } \\
\text { Southern Africa }\end{array}$ \\
\hline Laura Piddock, PhD & @LauraPiddock & $\begin{array}{l}\text { Professor of Microbiology; Director of Antibiotic Action; British Society for } \\
\text { Antimicrobial Therapy Chair in Public Engagement }\end{array}$ \\
\hline Didier Pittet, MD & $@$ DidierPittet & Director of Infection Control Programme and WHO external lead \\
\hline Darryl Vine, MD & @EasyASP & Passionate about antibiotic resistance and metrics \\
\hline $\begin{array}{l}\text { Dena van den Bergh, BPharm, } \\
\text { MSc (Med), EngD }\end{array}$ & @inspired2leadQI & $\begin{array}{l}\text { Director of Quality Leadership Netcare; Certified Coach; Systems Innovation and } \\
\text { Improvement Advisor; Best Care ... Always co-founder }\end{array}$ \\
\hline \multicolumn{3}{|l|}{ Organisations } \\
\hline $\begin{array}{l}\text { - Centre for Disease Dynamics } \\
\text { and Economic Policy }\end{array}$ & $@ C D D E P$ & \\
\hline $\begin{array}{l}\text { - ReAct Action on Anti- } \\
\text { biotic Resistance }\end{array}$ & @reactgroup & \\
\hline - Antibiotic Action & @TheUrgentNeed & \\
\hline - Save Antibiotics & @saveantibiotics & \\
\hline $\begin{array}{l}\text { - The Alliance for the Prudent Use } \\
\text { of Antibiotics }\end{array}$ & $@$ APUANews & \\
\hline \multicolumn{3}{|l|}{ Journals } \\
\hline - Lancet Infectious Diseases & @TheLancetInfDis & \\
\hline - PLoS One & $@$ PLOSONE & \\
\hline $\begin{array}{l}\text { - Journal of the American } \\
\text { Medical Association }\end{array}$ & @JAMA_current & \\
\hline - New England Journal of Medicine & @NEJM & \\
\hline
\end{tabular}


into the gravity of the epidemic faster than any other method of communication. The Ebola epidemic identified the importance of having access to real-time on-the-go information during an epidemic. In the USA, the CDC used Twitter to provide Ebola updates in real-time.

\section{How do you get started on Twitter?}

Getting started on Twitter is quick and easy. First-time users may go to www.twitter.com to sign up and create a free account. Once the account is registered, the Twitter app may be used on a smartphone. For a detailed description of Twitter terminology and how to get started, click on the following link: http://bcpsqc.ca/blog/knowledge/twitterfor-health-care-professionals/

We recommend uploading your photo and writing a brief biographical sketch that identifies you as a physician, pharmacist, nurse or HCP. The key to unleashing the power of Twitter is finding the right people to follow. Remember, you will receive every tweet from each person you follow, so it is wise to look at what they tweet prior to following them. Table 1 includes a selected list of reputable people and organisations who regularly tweet about AMR, and medical journals to follow on Twitter.

\section{How is Twitter used} as a learning tool for healthcare providers?

Twitter provides a dynamic way to share ideas, collaborate and connect with others, educate and build a global healthcare network. The following four topics demonstrate the application of Twitter for HCPs:

- Medical conferences. Surgeons, oncologists, cardiologists and urologists are among attendees at non-infectious diseases specialist conferences, who tweet live from a conference to help to disseminate information in realtime and increase the reach. Tweets from conferences will reach members who are not able to attend. It also helps to multiply the impact of scholarship by retweeting messages. At the 2013 American College of Surgeons conference, 434 tweets from the meeting produced 474776 impressions or views by followers who retweeted the original tweet. ${ }^{[9]}$

- International journal clubs. Twitter journal clubs provide a unique platform for engagement between HCPs worldwide. Urologists have been one of the first to host an international journal club. ${ }^{[10]}$ The organisers select an article from a peer-reviewed journal. Key opinion leaders or the article's author leads the Twitter chat. Anyone with an internet connection and a Twitter

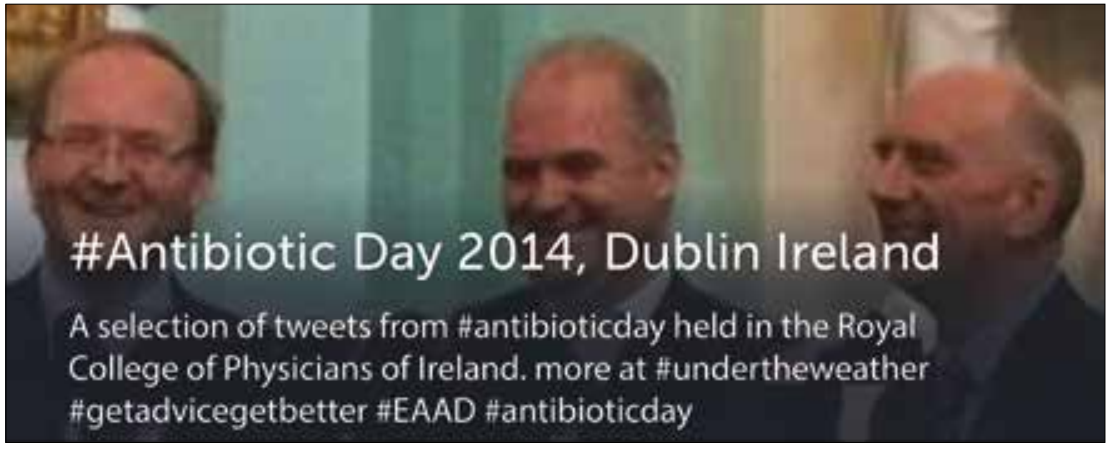

Fig. 2. Irish physicians participate in the Centers for Disease Control \#antibioticday chat. Click on the following link to view their summary of the Twitter chat: https://storify.com/FfitzP/antibioticday-2014-dublin-ireland?utm_content=storify-pingback\&utm_medium =sfy.co-twitterdutm_ campaign=\&utm_source=t.co\&awesm=sfy.co_e00jY

Save Antibiotics Bsaveantibiotics - Dec 14

Staggering global deaths and costs due to superbugs predicted in new report. ow.ly/FOKiu

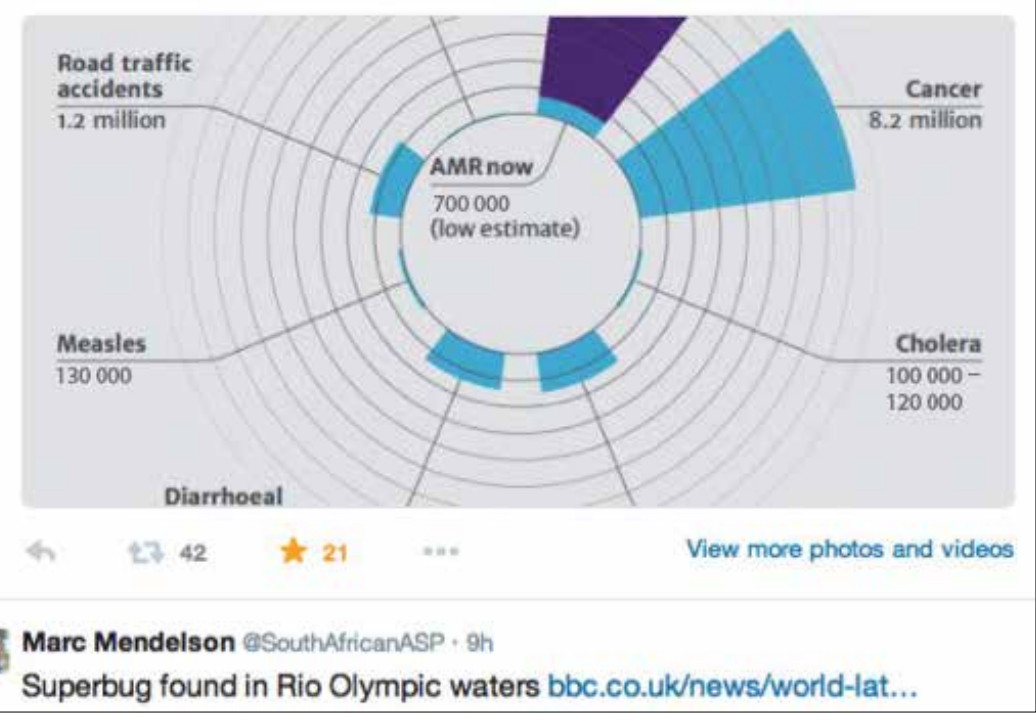

Fig. 3a. Full articles may be accessed from tweets by clicking on the blue links.

account can participate or monitor the discussion that occurs via tweets. The tweets are indexed using the journal club hashtag (\#urojc). They currently have $>2650$ followers, who generate a mean of 130832 impressions each month, far exceeding the traditional reach of journal clubs held in hospitals. An international journal club on AMR would be valuable, as every new and emerging infectious disease is just a plane ride away.

- Twitter chats. A Twitter chat is a 'live' event that is moderated by an expert and focuses on a particular topic. A predetermined hashtag (\#) is used in each tweet to follow the conversation. For example, as part of the 2014 CDC's Get Smart About Antibiotics campaign, the CDC hosted an antibiotic resistance-themed global Twitter chat using the hashtag (\#antibioticday). Fig. 2 shows physicians from Ireland who

\section{Marc Mendelson \\ QSouthAfricanASP Fousows you \\ Co-Chair South African Antibiotic Stewardship Programme President of the Federation of Infectious Diseases Societies of Southern Africa \\ U University of Cape Town () fidssa.co.za/A_SAASP_Home.a... \\ $T / S$ Twoot to † Mossage}

Fig. 3b. Example of a Twitter profile.

participated in the CDC \#antibioticday chat. Twitter chats allow experts to field questions from a global audience of HCPs, consumers, patients, policy makers and journalists. Furthermore, it increases the awareness of AMR to a global audience. 
- Networking. Twitter can help to build professional relationships with people you may never meet outside the virtual world. HCPs share an extremely wide range of tweets with links to articles, photos, and YouTube videos. It is not unheard of for colleagues collaborating on research projects to have met via Twitter. Twitter has enabled experts to communicate their research quickly and efficiently throughout each corner of the world. It provides a voice to HCPs who may not publish in peer-reviewed journals, but have many worthwhile thoughts or recommendations to share. The user may click on the blue links that will take them to a full article (Fig. 3a). A tweet may be saved for future viewing by clicking on the yellow star. This tags the tweet as a 'favourite' and also alerts the person who sent the tweet that you 'favourited' or liked the tweet. An example of a Twitter profile is given in Fig. 3b.

\section{What are the risks of using Twitter as a healthcare provider?}

HCPs must realise that as healthcare professionals their tweets are held to a higher standard. Always tweet responsibly and professionally. Remember, what appears on Twitter stays on Twitter forever. Never tweet information that could identify a patient and breach patient confidentiality. We recommend avoiding giving medical advice, as the 140-character limitation of a tweet may preclude writing a thorough response. Twitter, as all social media, is susceptible to inaccurate and erroneous messages. Always read links before retweeting messages from sources you do not know.

\section{How do I overcome my fear of using Twitter?}

Over 152000 tweets per day are sent from 75000 physicians, pharmacists, nurses and healthcare consultants. ${ }^{[11]}$
Click on the following link to see the uptake of Twitter by HCPs in Africa and around the world: http://www.creationpinpoint.com/ worldwide-doctors-on-twitter-explore-the-data/

Do not let the world pass you by. Now is the time to help to make a difference in the fight against AMR. Twitter is a vehicle that can connect the world and help to win the battle against AMR.

\section{References}

1. Mayosi BM, Benatar SR. Health and health care in South Africa - 20 years after Mandela. N Engl J Med 2014;371(14):1344-1353. [http://dx.doi.org/10.1056/NEJMsr 1405012]

2. World Health Organization (WHO). WHO Antimicrobial Resistance: Global Report on Surveillance, April 2014. www.who.int/drugresistance/documents/surveillancereport/en/ (accessed 2 December 2014).

3. Mendelson M, Matsoso M. A global call for action to combat antimicrobial resistance: Can we Mendelson M, Matsoso M. A global call for action to combat antimicrobial resistance: Can we
get it right this time? S Afr Med J 2014;104(7): 478-479. [http://dx.doi.org/10.7196/samj.8534] 4. CDC Vital Signs Report, March 2014. www.cdc.gov/vitalsigns (accessed 30 November 2014).

5. Goff DA, Mendelson M. Is it time for antibiotic prenuptial agreement? Lancet Infect Dis 2014;14:11681169. [http://dx.doi.org/10.1016/S1473-3099(14)70992-2]

6. Review on Antimicrobial Resistance. Antimicrobial resistance tackling a crisis for the health and wealth of nations 2014. http://amr-review.org/sites/default/files/AMR\%20Review\%20Paper\%20 $-\% 20$ Tackling $\% 20 \mathrm{a} \% 20$ crisis\%20for\%20the\%20health\%20and\%20wealth\%20of\%20nations_1.pdf (accessed 3 December 2014)

7. World Wide Worx. http://www.worldwideworx.com/wp-content/uploads/2013/10/Exec-Summary-SocialMedia-2014.pdf (accessed 30 March 2015)

8. Symplur. http://www.symplur.com/healthcare-hashtags/ebola/ (accessed 24 October 2014).

9. Cochran A, Kao LS, Gusani NJ, et al. Use of Twitter to document the 2013 Academic Surgical Congress. J Surg Res 2014;190:36-40. [http://dx.doi.org/10.1016/j.jss.2014.02.029]

10. Thangasamy IA, Leveridge M, Davies BJ, et al. International Urology Journal Club via Twitter: 12-month experience. Eur Urol 2014;66:112-117. [http://dx.doi.org/10.1016/j.eururo.2014.01.034]
12

11. Creation Pinpoint. http://www.creationpinpoint.com/how-we-differ/big-hcp-data/ (accessed 4 November 2014).

Additional educational resources

Best Care Always. http://www.bestcare.org.za

Getting started with Twitter. https://support.twitter.com/articles/215585-getting-started-with-twitter

Goff DA, Kullar R, Newland J. Review of Twitter for infectious diseases clinicians: Useful or a waste of time? Clin Infect Dis 4 February 2015. [Epub ahead of print] [http://dx.doi.org/10.1093/cid/civ071] South African Antibiotic Stewardship Programme (SAASP). http://www.fidssa.co.za/A_SAASP 